\title{
NOTE ON A FAMILY WITH BRACHYDACTYLY
}

\author{
BY \\ ROBERT MARSHALL, M.D., F.R.C.P.I., D.P.H. \\ Physician, Ulster Hospital for Children and Women, Belfast.
}

The accompanying photographs show brachydactyly of both hands and feet in a child, its mother and aunt ; the great-grandmother, grandmother and uncle are said to have presented similar deformity. The shortening of the of the digits is of the type associated with apparent absence of the middle phalanges. The mother is unable to state whether any other members of the family have been affected.

Brachydactyly is a deformity of more than usual interest for two reasons : first, because Bateson ${ }^{1}$ states that it is the first human condition found to obey Mendelian laws, being a dominant characteristic ; and secondly, because there appears to be a considerable number of different forms of brachydactyly.

Feil $^{2}$ states that diminution in the length of the fingers is much more rare than other malformations such as polydactyly and ectrodactyly; that the hands are more commonly affected than the feet; and that one or both hands and one or several digits may be involved. He classifies the condition into :-

(1) Brachydactyly by simple shortening of the digits, the number of bones remaining normal.

(2) Brachydactyly by ankylosis of the bones of the digit.

(3) Brachydactyly by partial loss of bone, either in metacarpus or phalanges.

Drinkwater ${ }^{3}$ describes a Liverpool family in which there occurred in several generations a brachydactyly exactly like that illustrated herewith. He considered that the second phalanx is not really absent, but at a certain stage of development has united with the terminal phalanx to form a bone of which 'the pyramidal distal portion corresponds to the ungual phalanx and the basal cubical portion ot the middle phalanx.' In the case here reported (Figure 9), there appear to be rudimentary middle phälanges which have not fused with the terminal ones. I have been unable to trace any kinship between the Liverpool family and the Belfast family which I describe.

Gilmore ${ }^{4}$ describes a family where one child had two phalanges for each finger, but had normal feet, and whose brother had other deformities such as webbed toes or absence of nails. 
Fig. 1. Table showing incidence of l,rachydactyly.

Fig. 2. Photograph of the child, held by the mother.

Figs. $3 \& 4$. Radiograms of the child's foot and hand. 


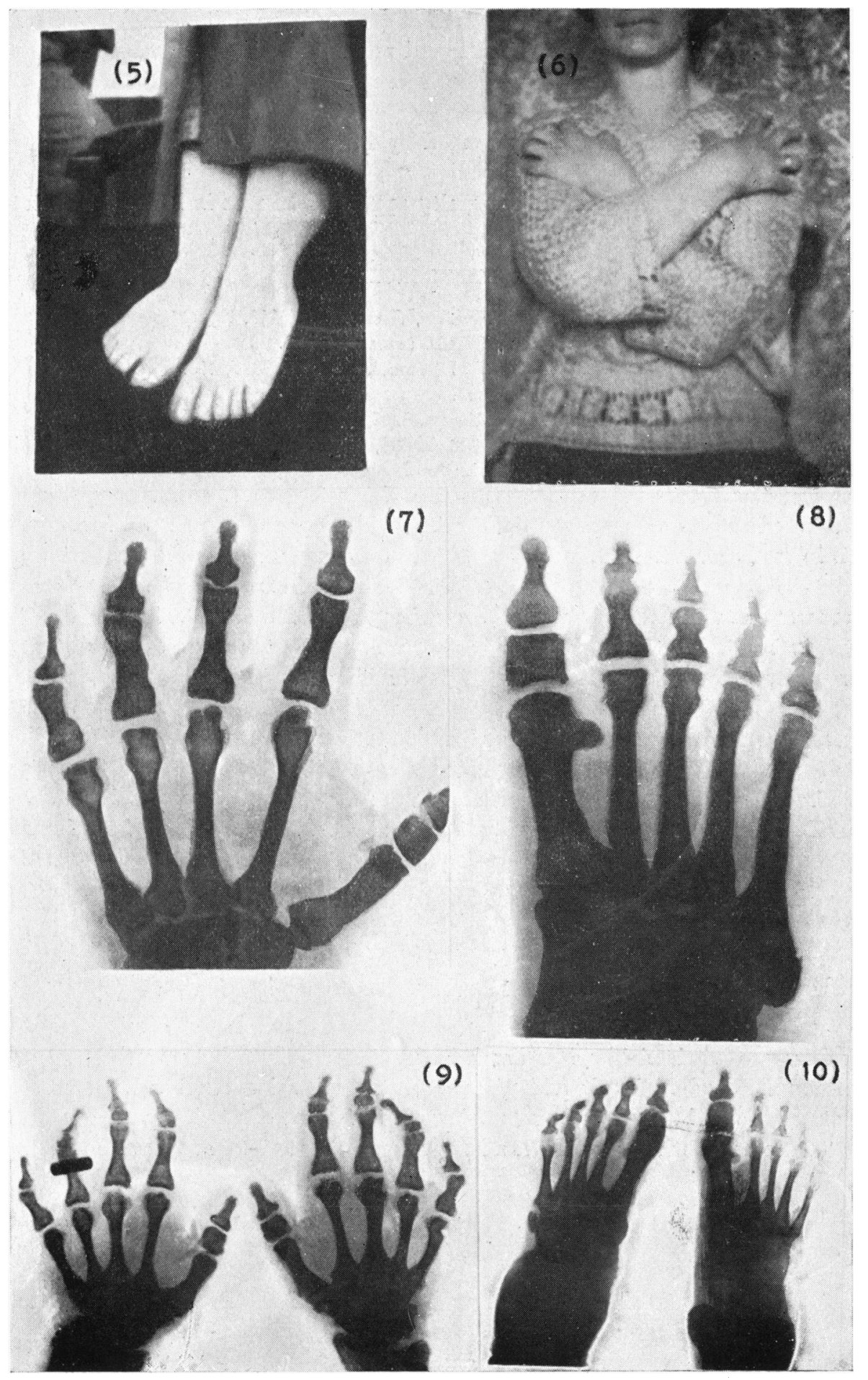

Figs. 5 \& 6. The mother's feet and hands.

Figs. $7 \& 8$. Radiograms of the mother's hand and foot.

Figs. $9 \& 10$. Radiograms of the aunt's feet and hands. 
Walker $^{5}$ reported a family in which there occurred imperfect union of first and second phalanges in the ring and middle fingers. Feil ${ }^{2}$ says that the phalangeal types of brachydactyly are less rare than those in which there is shortening of one or more of the metacarpal bones (usually that of the ring finger). Such cases have been reported by Boorstein ${ }^{6}$ and Wagner ${ }^{7}$ amongst others.

References to this curious deformity appear to be rare in English medica! literature.

\section{REFERENCES.}

1. Bateson, W., Mendel's Principles of Heredity, Camb., 1913, 210.

2. Feil, Presse Medicale, Paris, 1924, XXXII (annexe), 1451.

3. Drinkwater, H., Liverpool Med.-Chir. J., Liverpool, 1908, XXVIIJ, 408.

4. Gilmore, Brit. Med. J., Lond., 1927, 935.

5. Walker, G., Johns Hopliins Bull., Baltimore, 1901, XII, 123.

6. Boorstein, Surg. Gynocc. Obst., Chic., 1926, XLIII, 654.

7. Wagner, H., Fortschritte auf dem Gebeite der Rontgenstrahlen, Hamburg, 1904. 